\title{
CONCEPCIONES SOCIALES Y POLÍTICAS DE LOS TERRITORIOS MBYÁ GUARANÍ ALGUNOS ELEMENTOS ACTUALES PARA SU CONSIDERACIÓN.
}

\author{
CAROLINA RODRIGUEZ
}

\begin{abstract}
RESUMEN
Este trabajo presenta algunos de los elementos relevantes que hacen a las nociones y prácticas territoriales mbyá actuales, intentando mostrar que los usos y formas de ocupación espacial atraviesan las definiciones hegemónicas del territorio. Se parte de un análisis etnográfico considerando los casos particulares de comunidades o tekoa mbyá ubicadas en los Departamentos de Caazapá e Itapúa, Paraguay, junto a las cuales hemos realizado proyectos de relevamiento territorial. En un contexto de transformación radical de los territorios a partir del avance de la agroindustria, los mbyá desenvuelven sus modos propios de vida social, económica, política y religiosa, también reconfigurando nociones y prácticas territoriales en relación a la sociedad envolvente. Los marcos de referencia mbyá son redefinidos constantemente en las relaciones que mantienen las comunidades entre sí y con los jurua (noindígenas), y los demás seres presentes en el entorno.
\end{abstract}

\section{PaLABAs CLAVE}

Territorio; tekoa; comunidad, organización social y política.

\section{CONCEPÇÕES SOCIAIS E POLITIICAS DOS TERRITÓRIOS DE MBYÁ GUARANI:: ALGUNS ELEMENTOS ATUAIS PARA ANÁLISE}

\section{RESUMO}

Este artigo apresenta alguns dos elementos relevantes que formam as noções e práticas territoriais Mbyá atuais, procurando demostrar que os usos e formas de ocupação espacial estão atravessadas pelas definições hegemônicas do território. A partir de uma análise etnográfica, se considera os casos específicos de aldeias ou "tekoa" Mbyá localizadas nos departamentos de Caazapá e Itapúa (Paraguai), com quem realizamos projetos de levantamento territorial. No contexto da transformação radical dos territórios debido ao avanço da agroindústria, os Mbya desenvolvem seus modos de vida sociais, econômicos, políticos e religiosos, reconfigurando noções e práticas territoriais próprias em relação à sociedade envolvente. Os quadros de referência Mbyá são constantemente redefinidos nas relações que as comunidades têm entre eles, com os jurua (não indígenas) e os demais seres presentes no entorno.

\section{PALAVRAS CHAVE}

Território, tekoa, aldeia, organização social e política.

\footnotetext{
${ }^{1}$ Bióloga, estudiante de Antropología Social, Universidad Nacional de San Martín (UNSAM), Buenos Aires, Argentina. Becaria doctoral del Consejo Nacional de Investigacioens Científicas y Técnicas (CONICET).caroliroes@gmail.com
} 


\begin{abstract}
This work introduces some of the most relevant elements that make up the current territorial notions and practices of the mbyá, in an attempt to show that the uses and ways of land occupation exceed the hegemonic definitions of territory. The basis is an ethnographic analysis that considers individual cases of communities or tekoa mbyá, located in the Caazapá and Itapúa departments in Paraguay, with which we have conducted a territorial survey. In a context of radical transformation of the territories, given the agribusiness advancement, the mbyá develop their own ways of social, economical, political and religious life, also reconfiguring territorial notions and practices in relation to the surrounding society. The mbyá frameworks are constantly redefined in the relationships they hold among their communities and with the jurua (non-indigenous), and other beings in the environment.
\end{abstract}

\title{
KEY WORDS
}

Territory, tekoa, community, social and political organization.

\section{CONCEPTIONS SOCIALES ET POLITIQUES DES TERRITOIRES DE MBYÁ GUARANII: QUELQUES ÉLÉMENTS ACTUELS POUR VOTRE CONSIDERATION}

\begin{abstract}
RÉSUMÉ
Cet article présente certains des éléments les plus pertinentes qui font aux notions et pratiques territoriales mbyá actuelles, en essayant de montrer que les habitudes et formes d'occupation spatiale passent par les définitions hégémoniques du territoire. On part d'une analyse ethnographique en considérant les cas particuliers des communautés ou tekoa mbyá situées dans les Départements de Caazapá et Itapúa, Paraguay, avec lesquelles on a réalisé des projets d'enquête territoriale. Dans un contexte de transformation radicale des territoires à partir du progrès de l'agro-industrie, les mbyá développent leurs propres modes de vie sociale, économique, politique et religieuse, en reconfigurant aussi des notions et pratiques territoriales en relation avec la société qui l'entoure. Les cadres de référence mbyá sont redéfinis constamment dans les rapport qui ont les communautés entre elles et avec les jurua (non indigènes), et avec les autres êtres présents dans l'environnement.
\end{abstract}

\section{MOTS CLÉS}

Territoire; tekoa; communauté, organisation sociale et politique. 


\section{INTRODUCCIÓN}

Existen distintas fuerzas en tensión que definen los territorios, donde los marcos de referencia mbyá son redefinidos y conjugados permanentemente con prácticas y acontecimientos particulares. En este texto apunto a desarrollar algunos de los varios elementos que hacen a los conceptos y a las prácticas relacionadas con la territorialidad mbyá. Me referiré a los casos específicos de comunidades mbyá ubicadas en los Departamentos de Itapúa y Caazapá, Paraguay, con quienes he trabajado. No incluyo de manera suficiente las actividades consideradas como "no tradicionales", como puede ser el arrendamiento de tierras para cultivos mecanizados; pues no cuento con experiencia en estos casos². Busco delinear en términos generales las posibles nociones de uso y ocupación observadas. Las concepciones y prácticas territoriales mbyá tienen que ver con modos de relacionamiento donde los espacios son concebidos a partir de sus formas propias de interacción con el mundo, no rigiéndose por una dicotomía naturaleza/cultura. Dicha interacción no se limita a "los mbyá" como conjunto homogéneo; implica negociaciones, alianzas y consideraciones de los mbyá entre sí, con otros grupos indígenas y con los jurua (no-indígenas). Ante la pérdida acelerada de sus espacios, a partir del avance expansivo de la agroindustria en las últimas décadas, las comunidades se organizan de varias maneras para defender y sostener su autonomía sociocultural y políticoreligiosa.

\section{DATOS DE CONTEXTO}

En Paraguay existen actualmente 117.150 personas $-1,8 \%$ de la población nacional (DGEEC, 2014, p. 49)- que pertenecen y se autoidentifican con uno de los 19 pueblos indígenas que viven en el país. La Región Oriental paraguaya está mayormente habitada por los grupos guaraníes ava, mbyá y paĩ tavyterã, teniendo cada uno características propias y particulares. Los mbyá, como ha sido registrado (REHNFELDT, 2013; SALAMANCA, 2012; MELIÁ, 2011; LADEIRA, 2008; MURA, 2006; PISSOLATO, 2006; GARLET, 1997), han ocupado y ocupan un gran espacio geográfico, independiente de las fronteras nacionales de Paraguay, Argentina o Brasil. En Paraguay son 20.546 personas y corresponden al pueblo indígena de mayor población, con 170 comunidades registradas según el último censo (DGEEC, 2014, p. 51). La falta de aseguramiento de sus tierras y territorios es una de las principales problemáticas con la que siguen lidiando, cada vez con más urgencia. El avance del frente agroindustrial intensivo en las últimas décadas

\footnotetext{
${ }^{2}$ Revisar el estudio de Bogado et al. (2016).
} 
(30-50 años) ha producido la acelerada fragmentación y achicamiento de territorios indígenas y campesinos. En Paraguay la superficie de siembra de monocultivos se estima que supera las 3.300.000 hectáreas (CAPECO, 2015) ocupando cerca del 80\% de las tierras destinadas a la agricultura (CAN, 2008). El 46\% de las comunidades indígenas que se han registrado no poseen título de propiedad de sus tierras (DGEEC, 2013). El territorio es una dimensión de reivindicación fundamental para las organizaciones indígenas en sus luchas actuales. En estos contextos, por otro lado, los territorios mbyá no están definidos únicamente como recurso material.

\section{ANTECEDENTES Y MÉTODOS}

En el año 1992 el Estado paraguayo crea la Reserva para Parque Nacional San Rafael (RPNSR), unas 78.000 ha ubicadas entre los Departamentos de Itapúa y Caazapá. Esto se realizó sin participación ni consulta a las comunidades mbyá que habitan en ese lugar, y violando la legislación vigente. Varias denuncias fueron realizadas por las comunidades. Como fruto de negociaciones entre el Estado y dos organizaciones mbyá, Asociación de Comunidades Indígenas de Itapúa (ACIDI) y Asociación Tekoa Yma Jee'a Pavẽ (TYJP), entre otras cosas, se firmó un acuerdo de cooperación que derivó en un proyecto de mapeo participativo. La ACIDI se constituye jurídicamente en el año 1997, nuclea alrededor de 24 comunidades mbyá y TYJP se conforma en el año 2000, articulando 8 comunidades mbyá3. Las Asociaciones se han conformado "con un objetivo muy claro: la lucha territorial" (Propiedad Intelectual del Pueblo Mbyá Guaraní, 2013, p. 10). Durante el proyecto, se elaboraron mapas (años 2012 y 2013) para apoyar el reclamo territorial de 26 comunidades en la zona declarada Parque, reivindicada como Tekoha Guasu (Fig. N¹). Luego surge un segundo mapeamiento (año 2016) en 7 comunidades del Departamento de Caazapá, esta vez junto a TYJP (Fig. N²). Los resultados fueron publicados en tres documentos (Propiedad Intelectual Colectiva del Pueblo Mbyá Guaraní, 2009, 2013, 2016) que contienen la metodología construida participativamente, los mapas, testimonios e información detallada, siendo las comunidades y Asociaciones mbyá las protagonistas de los relevamientos. Estos trabajos también se presentaron (RODRíGUEZ y GLAUSER, 2014; GLAUSER, 2012) haciendo hincapié, desde un enfoque agroecológico, en las prácticas relacionadas a la agricultura, la cacería, la pesca y la recolección. Quisiera aproximarme en el presente trabajo a algunos de los aspectos políticos y sociales registrados. Durante los proyectos de mapeo participé como técnica de la ONG Altervida. Desde mi lugar me encontré observando y siendo parte de un complejo entramado de relaciones sociales y políticas entre el

\footnotetext{
${ }^{3}$ El número de comunidades que hacen parte de cada Asociación puede estar desactualizado.
} 
Estado, la sociedad paraguaya, las asociaciones mbyá, otras ONGs. Cada colectivo era portador de una visión particular que explicaba la situación territorial. Esto lleva a señalar que la noción de territorio es una construcción compleja. Luego, a principios de 2016, cuando el equipo de Altervida se retiraba una vez terminado el mapeo, yo permanecía en una de las comunidades, lo cual me dio un acercamiento distinto de mi papel como técnica. Pude conocer una dimensión cotidiana donde cobraron preponderancia las actividades diarias, relaciones cotidianas. Parto desde un enfoque etnográfico (GUBER, 2001), entendido como aquella forma de conocimiento antropológico que se centra en la perspectiva de los actores locales, buscando comprender sus puntos de vista. Puesto que la perspectiva de los actores es una construcción analítica (BALBI, 2012) no será la perspectiva mbyá en su forma cabal, sino una construcción de la investigadora acerca de lo que dicen y hacen estas personas.

Fig. N 1: Zona de mapeo y comunidades en el Tekoha Guasu.

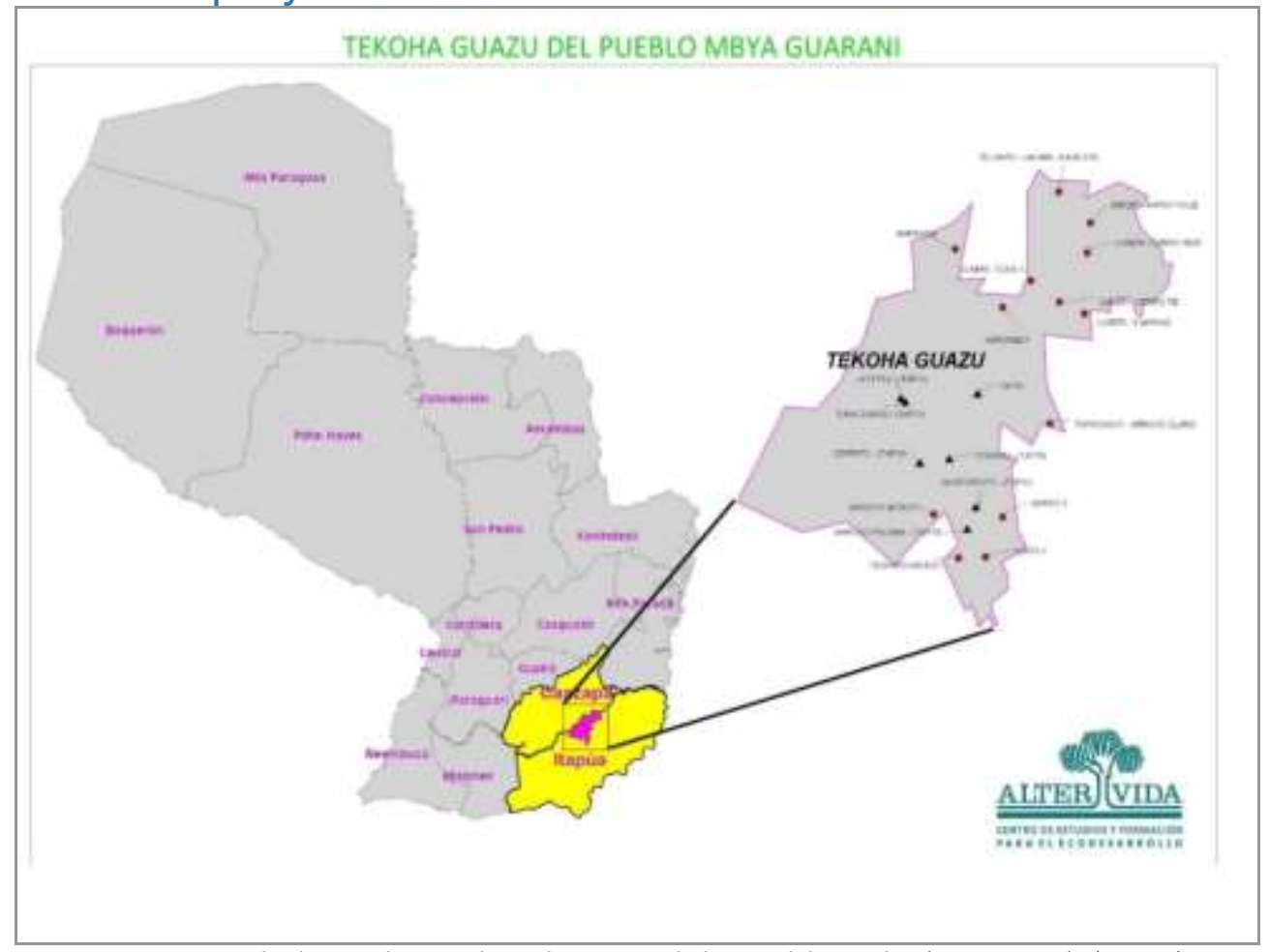

Fuente: Propiedad Intelectual Colectiva del Pueblo Mbyá Guaraní (2013). En 2012, 13.093 ha, no contiguas, se encuentran a nombre de las comunidades mbyá. ACIDI y TYJP reivindican unas 100.000 ha; aclaran que su territorio incluye y supera el área decretada como RPNSR. 
Fig. № 2: Zona de mapeo en el Departamento de Caazapá.

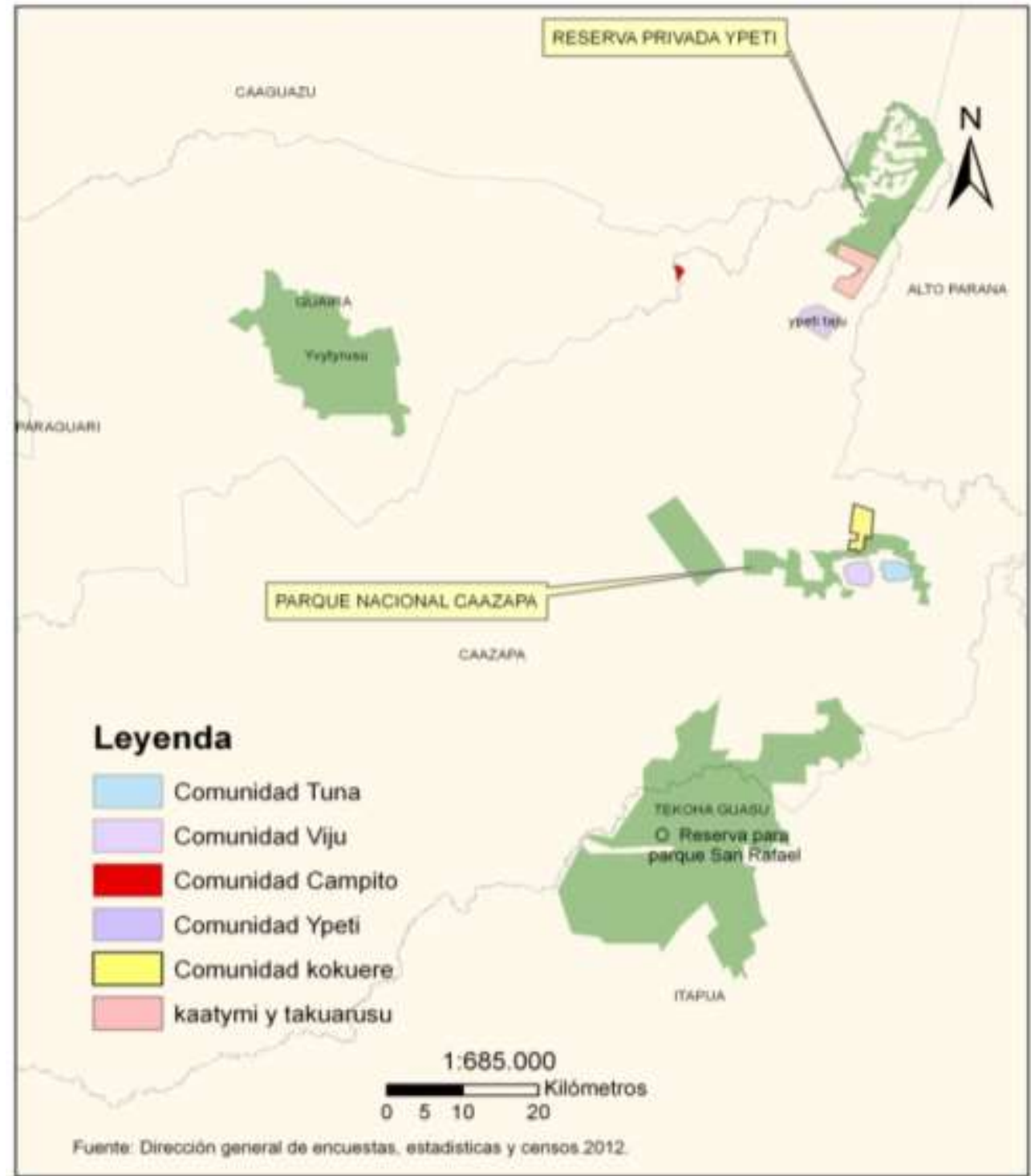

Fuente: Propiedad Intelectual Colectiva del Pueblo Mbyá Guaraní (2016). Las comunidades se distribuyen en grandes extensiones de monocultivos y pueblos de colonos brasileros. Algunas colindan con Parques Nacionales o Reservas Privadas, con las que también se encuentran en conflicto. De las comunidades mapeadas, 6 tienen títulos de propiedad contabilizando 4.994 ha, no contiguas.

\section{CONSIDERACIONES SOBRE LA NOCIÓN DE "TEKOA"}

Tekoha o tekoa es una palabra guaraní históricamente registrada en la literatura, traducida como "lugar que hace posible el teko o modo de ser guaraní" (MELIÁ, 1986, 2011; LADEIRA, 2008; LARRICQ, 1993; CHASE-SARDI, 1989). Los trabajos de Bartomeu Meliá proponen el tekoha como "lugar", lo cual proyecta, en términos conceptuales, una categoría espacial que 
expresa algún territorio definido, cuestión discutida por algunos autores y autoras (PISSOLATO, 2006; MURA, 2006). Meliá (2011, p. 135) indica que para los guaraníes "la tierra, concebida como tekoha, es ante todo un espacio sociopolítico y cultural". Beate Lehner $(2005,2008)$ sostiene que cada persona guaraní es parte de una red extensa de parentesco que comparte un territorio común, siendo el tekoha el territorio que un grupo de parientes habita y que considera para su uso exclusivo. Este territorio tiene connotaciones socio-políticas según las pautas guaraníes del "modo de ser" o "teko". "Tekoha"y "teko"se encuentran relacionados y son interdependientes en sus definiciones, según la literatura. Meliá et al. (2008, p. 131) observan que "tekoha" puede "variar en superficie" pero "estructura y función se mantienen igual". Fabio Mura (2006) señala que la noción actual del tekoha en cuanto "lugar donde realizamos nuestro modo de ser" incluye reflexiones de los guaraníes acerca de las transformaciones y los conocimientos adquiridos en la interacción con las sociedades no-indígenas. Mura critica que los tekoha se "mantengan iguales en estructura y función" aún con el paso del tiempo y el cambio en los contextos locales. En los últimos treinta años los territorios ocupados por los mbyá en Paraguay han sufrido cambios radicales a partir del avance de la agroindustria. Esto ha afectado sus instituciones sociales, generando respuestas y estrategias políticas propias. La conformación de los tekoa siguiendo un teko, no están determinados de una vez y de manera absoluta, sino que incluye identidades y definiciones móviles.

\section{TEKOA Y COMUNIDAD INDÍGENA}

Cada persona guaraní pertenece a una familia y a un tekoa, y se corresponde a un grupo local (SUSNIK, 1998; LEHNER, 2008). La familia extensa es la unidad base de organización social, política y territorial guaraní (LEHNER, 2005; MURA, 2006). Una familia extensa está generalmente constituida por la pareja y sus hijos e hijas, y las parejas e hijos respectivos de éstos. El tamaño de las familias extensas varía, y depende, también, del poder aglutinante de la pareja que encabece la familia (LEHNER, 2005). Las familias muy numerosas se dividen en grupos más pequeños que se ubican próximos entre sí. Marcelo Bogado (2017) indica que aunque la familia extensa es la dueña de los recursos dentro del espacio habitado, la unidad de producción mbyá, constituida antes por esta familia extensa, actualmente la conforma la familia nuclear (madres, padres e hijos). Las familias nucleares que se asientan próximas a las casas de los abuelos y abuelas, y generalmente poseen sus propias chacras. Una o más familias extensas forman comunidades o tekoa.

Los tekoa poseen espacios internos donde se encuentran las óga kuéry (casas), las kokue (chacras), las fuentes de agua, los lugares de uso común (como escuelas, salones 
comunitarios); el ka'aguy (monte). Estos espacios se comunican a través de tape po'i (pequeños caminos). Los "caminos principales" conducen a los espacios externos, como pueblos y ciudades cercanas, donde se encuentran los centros de salud, comercios, hospitales. Esta organización se encuentra en muchas de las comunidades mbyá visitadas (Fig. № 3). Varias comunidades ubicadas en el Tekoha Guasu se conectan por tape po'i que atraviesan los montes de las comunidades o propiedades vecinas. En zonas donde las comunidades quedaron separadas por campos de monocultivos se utilizan los caminos principales para establecer conexiones y visitas entre sí. Los territorios mbyá deben ser entendidos como lugares que van más allá de las áreas específicas donde se encuentran sus casas y comunidades.

Los tekoa son particulares y autónomos, con autoridades propias. En algunas comunidades se hacen reuniones cada quince días, me indicaron. En éstas se discuten "trabajos que se están haciendo, actividades, responsabilidad de cada persona, cómo están las cosas y cómo están funcionando las personas en sus funciones. Se hace seguimiento completo". Cada tekoa tiene un líder político visible, y cuenta, en su gran mayoría, con la presencia de líderes religiosos. Los líderes religiosos tienen la habilidad y el conocimiento para comunicar a la comunidad con las entidades divinas. Los ancianos y las ancianas, Che Ramói/Jarýi, son respetados como autoridades, siendo especialmente considerados tanto en decisiones políticas respecto al relacionamiento con otros tekoa o no-indígenas, como dentro de las actividades y en el accionar cotidiano. El líder político es reconocido por su grupo de parentesco, aunque ésta no es la única condición. Es el trabajo constante en la producción de consenso del grupo lo que mantiene los liderazgos (KRAMER, 2006). Anteriormente, cuando se presentaban conflictos entre grupos al interior de los tekoa, éstos se solucionaban con la fundación de uno nuevo, fuera del territorio del tekoa de origen (LEHNER, 2005, p. 31). En el escenario de expansión agroindustrial, ocurre que varios tekoa terminan ubicados dentro de una misma Comunidad Indígena, o bien un tekoa se divide en varias Comunidades Indígenas (MELIÁ et al., 2008). Esto nos lleva a algunas consideraciones. Los términos tekoa y Comunidad Indígena a veces pueden coincidir. La "Comunidad Indígena" es una categoría legal reconocida por el Estado a partir de la Ley 904/81, con personería jurídica para la titulación y tenencia de tierras. Dentro de una Comunidad Indígena pueden encontrarse dos o más familias extensas formando grupos que disputan el liderazgo político. Esto muestra que los tekoa no son unánimes en sus maneras de accionar, ni los líderes en sus estrategias políticas.

Los liderazgos mbyá son fluidos y móviles, resultando de las prácticas cotidianas y de estilos de liderazgos reconocidos por las personas que los siguen. Los condicionamientos que impone la configuración territorial impactan en algunos aspectos. Anteriormente, se podían 
fundar nuevos tekoa cuando se veía la necesidad de hacerlo, lo que en el escenario actual no es posible. Además, los límites fijos de las Comunidades Indígenas son requeridos de manera sistemática por los líderes para el aseguramiento de sus tierras, cuestión que antes no se veía como una necesidad. Algunos líderes mbyá señalan que: "Antes se vivía mejor. No teníamos grandes problemas, cuando había conflictos nos adentrábamos más al bosque y así solucionábamos nuestros problemas" (FAPI \& FPP, 2015, p. 30). Sin embargo, en el contexto de pérdida e invasión acelerada de sus territorios, garantizar tierras se hace urgente. Por otro lado, señalar que el cargo de "cacique" es reconocido en términos legales junto a la Comunidad Indígena, lo que a veces representa un problema para la flexibilidad de cambios en los liderazgos. El modelo de la Ley 904/81, que propone un líder por cada Comunidad Indígena, ha creado nuevos campos de conflicto ${ }^{4}$. Muchas veces el líder reconocido por el órgano estatal no cuenta con apoyo de la comunidad; o viceversa. Los tekoa y los grupos familiares mantienen distintos puntos de vista y opiniones, que complejizan las interacciones y permiten entender que "los mbyá" no componen una totalidad invariable y estática.

Fig. $N^{\circ}$ 3: Mapa comunitario. Casas, fuentes de agua, tape po'i; y los límites de la propiedad.

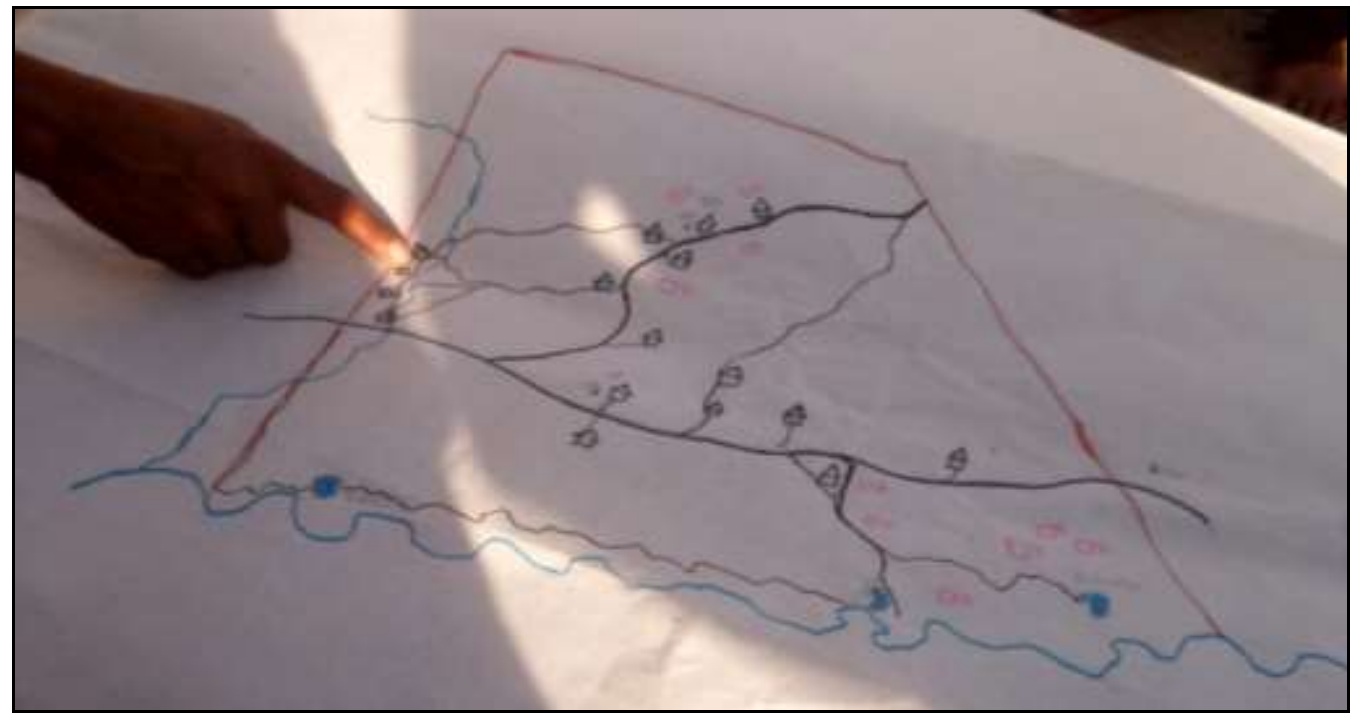

Fuente: Propiedad Intelectual Colectiva del Pueblo Mbyá Guaraní (2013).

$4 \quad$ Es importante aclarar que esta Ley significó un enorme avance y se dio a partir del movimiento Paĩ Tavyterã en los años 70, como resultado de una larga campaña. Gracias a ello se sentaron las bases legales del Capítulo dedicado a los Pueblos Indígenas de la nueva Constitución Nacional (1992), luego de la caída de la dictadura (1989). Sin embargo, fue aplicada a todas las sociedades indígenas, sin considerar sus diferencias (VERA, 2015). 


\section{LOS TEKOA EN CONJUNTO Y LAS ASOCIACIONES}

Los tekoa a su vez forman parte de conjuntos más amplios donde se establecen relaciones entre sí y con los jurua. Forman redes de parentesco que relacionan política, económica, familiar y religiosamente a los tekoa entre sí. Anteriormente se correspondían con espacios territoriales gobernados por un líder regional, según algunas fuentes (REHNFELDT, 2013; LEHNER, 2008; FAPI \& FPP, 2015). La existencia de estos líderes no implicaba que los tekoa respondan a éstos en todo momento. Estos líderes son hoy descritos como parte de tiempos pasados, aunque no distantes, como el gran líder mbyá Ángelo Garay (Propiedad Intelectual Colectiva del Pueblo Mbyá Guaraní, 2009, p. 21). Líderes mbyá indican: “El pueblo Mbya Guaraní es un pueblo transfronterizo... Antes vivíamos territorialmente. Teníamos grandes dirigentes territoriales. En esa época los líderes comunitarios eran pocos y ellos respondían a los jefes grandes. Nuestro territorio tradicional era extenso..." (FAPI \& FPP, 2015, p. 30).

Hasta los años 90 los Departamentos de Itapúa y Caazapá aun contaban con zonas boscosas. El avance de la agroindustria trajo consigo procesos de deforestación masiva y concentración de tierras. Estos cambios han impactado en la organización de los tekoa y los conjuntos amplios que forman. Lehner (2008b, p. 92) observa que el tekoha tradicional se fraccionó a su vez en varias comunidades políticamente autónomas. En este mismo sentido, Barbosa \& Mura (2011) muestran, para el caso de los guaraníes Kaiowa y Ñandeva, una tendencia en su organización que busca, traspasando fronteras territoriales, consolidar comunidades políticas locales que resultan de la segmentación de unidades políticas anteriores. Francisco Silva Noelli (1993) sostiene que en la actualidad no existen más tekoha que formen unidades geopolíticas. Pero en mi experiencia, las redes regionales entre los tekoa mbyá y sus estructuras políticas y sociales formando alianzas e intercambios están presentes.

Los tekoa actúan aliándose también en forma de Asociaciones, como ACIDI y TYJP. Estas organizaciones "modernas" tienen un Consejo Directivo y estructuras definidas (un estatuto) reconocidos legalmente por el Estado paraguayo. No obstante, la movilidad de los liderazgos aún dentro del Consejo es corriente. Los miembros de las Asociaciones pueden ocupar sus cargos indefinidamente o ser removidos, según se decida en las asambleas. Las Asociaciones se conforman como estructuras de 
coordinación y gestión que tienen un peso fundamental actualmente, en la zona donde he trabajado. Cabe señalar que cada Asociación tiene su particularidad. Los tekoa conforman Asociaciones y responden a ellas, pero cada tekoa puede aceptar o vetar las decisiones llevadas a cabo dentro de la Asociación, o incluso dejar de formar parte de éstas. Las decisiones que toma cada Asociación son consensuadas; y, en el caso de la Asociación TYJP, las decisiones se formalizan en asambleas generales llamadas aty guasu, a las que asisten los tekoa miembros. En estas grandes reuniones además, se llevan a cabo los tangara (rezos, danzas) y actividades religiosas en el Opy (casa ceremonial), en espacios reservados para los mbyá. Las reuniones llevadas a cabo en los aty guasu también incluyen espacios de articulación con los no-indígenas (entidades gubernamentales, ONGs, Pastoral Social). Por otra parte, hay varios tekoa que no forman parte de ninguna Asociación, aun cuando mantienen relaciones sociales, políticas, económicas, religiosas, con los tekoa miembros de éstas.

\section{NOCIONES, USOS Y OCUPACIÓN TERRITORIALES}

En un sentido reglamentario o ético, las formas de uso y ocupación de los territorios mbyá tienen que ver al menos con dos aspectos que han señalado las comunidades. Por un lado, un derecho originario sobre el ka’aguy(monte), otorgado por los creadores. Brígido Duarte, líder espiritual, narra: "En el principio nosotros fuimos los primeros que habitamos este monte, es que рага los Mbya fue creado el monte" (Propiedad Intelectual Colectiva del Pueblo Mbyá Guaraní, 2009, p. 57). Este derecho de uso de las creaciones, por otro lado, será aceptado siempre que esté en concordancia con las reglas definidas por el teko, donde la responsabilidad de uso se da no por una "consciencia ecológica en sí", sino una ética del teko (LADEIRA, 2008, p. 139). Una de las formas de relacionamiento ético se vincula con los jára kuéry. El referente mbyá Hilario Vera observó: "Hay lugares donde no entramos, como en los cerros, que tienen sus dueños muy celosos" (Propiedad Intelectual Colectiva del Pueblo Mbyá Guaraní, 2009, p. 31). Las Asociaciones ACIDI y TYJP indican que los jára kuéry. "Son los dueños de los recursos naturales y la vida, las estaciones, los diferentes tipos de suelo, los montes, las plantas sagradas, los diferentes animales, los cerros, cada parte del Tekoha Guasú de los Mbyá Guaraní. Los jára cuidan y protegen los recursos naturales y se debe pedir permiso a ellos para utilizarlos" (Propiedad Intelectual Colectiva del Pueblo Mbyá Guaraní, 2013, p. 87). 
Los jára vigilan y juzgan el accionar de los y las mbyá, siendo uno de los factores que regula el comportamiento de éstos para con las plantas, los animales, los lugares. Ante estas entidades se debe "tener respeto" a fin de no ser castigados, ya que pueden accionar de manera violenta cuando las reglas instrumentadas por ellos son transgredidas. Los modos de uso normativos son resaltados en los mapeos, y están presentes en sus formas de uso territorial, pero es importante señalar que los mbyá no se rigen exclusivamente por preceptos éticos. Éstos pueden ser o no cumplidos, según diversas situaciones particulares o consideraciones que realizan las personas. Las acciones de los mbyá que no se ajusten a las normas no implican que "dejen de ser indígenas". Durante los mapeos he observado varias entidades que proyectan imágenes idealizadas. En el caso de las comunidades mbyá, los "buenos" son los que defienden el monte, mientras que los "malos" son los que arriendan sus tierras para plantación de soja. Los líderes, comunidades y grupos indígenas en general, se involucran en los contextos de negociación y de cálculos en un universo de posibilidades, tomando las decisiones que consideran favorables según sus conveniencias, deseos, necesidades y exigencias. Esto implica decisiones ligadas a una "eficacia de uso, práctico y simbólico" (MURA, 2006, 2014) más que a un marco cosmológico estructurado o herméticamente definido. La relación que las comunidades tienen con sus territorios incluye negociaciones políticas, económicas y acciones de las personas tanto con los no-indígenas (ONGs o "sojeros"); como con los demás seres (animales, plantas, jára kuéry).

\section{TERRITORIO Y KA'AGUY (MONTE)}

Los territorios y los montes mbyá están habitados por diversos seres, humanos y nohumanos, que incluyen indígenas y jurua, espíritus, entidades consideradas "inertes" desde los parámetros de clasificación de la ciencia occidental, como los cerros, que poseen agencia y vitalidad, como observamos. Esto devela una red de relaciones sociales regidas por otras lógicas de comprensión del mundo, donde, para los guaraníes, la división entre lo "espiritual", "natural" y "cultural" es intrascendente (MURA, 2006, 2014; BADIE, 2013). Рara los mbyá la idea de territorio supera no solamente los límites físicos y geográficos de las comunidades, sino que se relaciona directamente con sus formas de relacionamiento social y con su filosofía y sociocosmología en general, en interacción con otros grupos sociales. El interés que tienen los mbyá en los montes es vital, no por compartir los mismos parámetros o categorías de "naturaleza", sino porque el monte es un espacio que les permite vivir según sus propios parámetros cosmológicos (LADEIRA, 2008, p. 51). La dimensión cosmológica, por otra parte, no tiene que ver con un corpus de conocimiento transmitido de forma invariable, sino que en su 
composición también intervienen experiencias personales y colectivas particulares. Un líder mbyá observó: "Nuestra meta es defender el territorio, eso es lo que hacemos. Si no había este proyecto, nosotros igual íbamos a defender. Nosotros queremos que nuestros niños se queden en nuestro tekoa" (durante el mapeo, 2013). Pero las comunidades y las organizaciones mbyá, además de valorar los montes, reivindican su derecho al acceso a tierras y territorios, que no pueden estar desvinculados, pues les permitan garantizar y definir libremente sus elecciones de vida.

\section{NOTAS SOBRE ACTIVIDADES COTIDIANAS Y AFECTIVIDAD}

Las actividades cotidianas y los aspectos del relacionamiento social, como la alegría, las visitas, son fundamentales en las nociones de espacialidad mbyá, pues construyen permanentemente las comunidades socio-políticas y la vida en los tekod. Una mañana estábamos sentadas en el patio de la casa, una chica joven, su hijo pequeño, y yo. Me contó que ella tuvo que salir de la comunidad varios meses, dejando a su bebé al cuidado de la abuela. Ante su falta el niño se enfermó, "mi bebé se puso muy mal", ndovy'ái (no se hallaba), me dijo. Desde que ella volvió se halla, empezó a subir de peso, a no enfermarse más. "Hallarse" ( $\left.v y^{\prime} a\right)$ refiere a sentirse bien. Varias observaciones (ENRIZ, 2010; REMORINI, 2010; PISSOLATO, 2006) destacan que el estar a gusto en un lugar, el $v y^{\prime} a$, es condición necesaria para el bienestar, interviniendo en los estados de salud y la pertenencia mbyá. Estos aspectos son constituidos entre las personas, sus relaciones y actividades diarias, componiendo una cotidianidad donde la tranquilidad y la alegría son altamente valoradas. Esta "tranquilidad" es entendida muchas veces como haraganería. "Los indios están sentados tomando terere todo el día, no quieren trabajar" (técnico de ONG, 2016). Sin embargo, no debe entenderse a los mbyá como personas pacíficas o totalmente íntegras en su actuar. Las acciones de las comunidades se rigen también por las exigencias e historias de las familias a las cuales pertenecen las personas, así como por las relaciones establecidas al "exterior" de los tekoa, que condicionan sus acciones de igual forma. Observamos que los tekoa tienen particularidades y autonomía en cuanto a sus estrategias económicas y alianzas políticas. Estas particularidades ocurren asimismo en el accionar cotidiano.

Las relaciones y la construcción de comunidades socio-políticas se dan también a partir de las visitas entre las personas. Se realizan visitas frecuentes entre familiares de otras comunidades, jóvenes en busca de parejas, referentes políticos para tratar conflictos si los casos lo ameritan, o por consultas a médicos o médicas mbyá. Además la movilidad puede darse cuando una familia entera se muda a otro tekoa, por ejemplo, cuando deja de seguir a un líder y se "cambia" de comunidad. Las relaciones sociales extendidas se despliegan por los territorios 
formando circuitos amplios que atraviesan las fronteras de Paraguay, Argentina y Brasil. La práctica de movilidad mbyá ha sido ampliamente registrada (BADIE, 2013; MELIÁ, 1986, 2011; ENRIZ, 2010; REMORINI, 2010; LADEIRA, 2008; SILVA, 2007; GARLET, 1997; KRAMER, 1982). Las dinámicas internas y actividades cotidianas suelen ser relegadas a los "espacios domésticos", a una dimensión secundaria. Lo cotidiano/doméstico y lo político/comunitario no funcionan como espacios opuestos y excluyentes en las comunidades, sino de manera continua. Habrá que abordar más detalladamente estos aspectos (OVERING \& PASSES, 2000), pues construyen el espacio, los modos de vida sociales, afectivos y políticos de los tekoa.

\section{CONCLUSIONES}

Los territorios mbyá se constituyen a partir de prácticas concretas que incluyen relaciones de las comunidades entre sí, con los no-indígenas y con los demás seres presentes en el entorno. Las dimensiones éticas de los usos y ocupación territorial, así como de la vida diaria ( $v y^{\prime} a$, relación con los jára kuéry) son fundamentales, pero no deben entenderse a partir de estructuras sociocosmológicas invariables. Los marcos de referencia también son redefinidos en contextos particulares. Las comunidades visitadas que hemos visitado presentan formas de organizar y sostener su autonomía sociocultural y político-religiosa en el contexto actual, donde se incorporan también elementos "foráneos" (títulos de propiedad, figura de Asociaciones). Los comportamientos mbyá no son homogéneos, existiendo diferencias, por ejemplo, entre liderazgos políticos. Las experiencias y trayectorias individuales y colectivas, las actividades diarias, los valores afectivos y los aspectos religiosos (como la importancia de los líderes religiosos, los rezos, tangara, el $O p y)$ orientan y configuran sus territorios, conjuntamente con las relaciones intercomunitarias y con los no-indígenas.

\section{REFERENCIAS:}

BADIE, Marilyn Cebolla. Cosmología y naturaleza mbya-guaraní. Tesis doctoral: Programa de Doctorado en Antropología Social y Cultural. Universidad de Barcelona. 2013.

BARBOSA, Pablo Antunha; MURA, Fabio. Construindo e reconstruindo territórios Guarani: dinâmica territorial na fronteira entre Brasil e Paraguai (séc. XIX-XX). Journal de la société des Américanistes, v.97, ก. 2, 2011.

BOGADO, Marcelo. Parentesco y diferenciación social entre los mbyá guaraní. Ponencia en Reunión de Antropología del Mercosur (RAM) XII. Posadas, Argentina: FHyCS-UNaM. 2017. 
BOGADO, Marcelo; PORTILLO, Rafael; VILLAGRA, Rodrigo. Alquiler de tierras y territorios indígenas en el Paraguay. Cadernos do Lepaarq, v. XIII, n. 26. 2016.

Cámara Рaraguaya de Exportadores y Comercializadores de Cereales y Oleaginosas. In: Capeco. Área de Siembra, Producción y Rendimiento, 2015.

UFSC, 2015.

Censo Agropecuario Nacional (CAN). Dirección de Censos y Estadísticas Agropecuarias: Paraguay, 2008.

CHASE-SARDI, Miguel. El tekoha. Su organización social y los efectos negativos de la deforestación entre los Mbyá- Guaraní. Suplemento Antropológico, v. XXIV, n. 2, 1989.

Dirección General de Estadística, Encuestas y Censo (DGEEC). Pueblos Indígenas en el Paraguay. Resultados Finales de Población y Vivienda 2012. III Censo Nacional de Población y Viviendas para Pueblos Indígenas. Fernando de la Mora, Paraguay. 2014. [2012].

Dirección General de Estadística, Encuestas y Censos (DGEEC). III Censo Nacional de Población y Vivienda para Pueblos Indígenas: Censo 2012 - Resultados preliminares. Asunción, Рaraguay. 2013.

ENRIZ, Noelia. Tomar asiento. La concepción y el nacimiento mbyá guaraní. Anthropologica, v. XXVIII, $n$. 28. p. 117-137, 2010.

Federación por la Autodererminación de los Pueblos Indígenas (FAPI) y Forest Peoples Programme (FPP). Situación Territorial de los Pueblos Indígenas de Paraguay. En: FAPI. 2015.

GARLET, Ivori José. Mobilidade Mbyá: historia e significação. Disertación de Maestrado, Pontificia Universidade Católica do Rio Grande do Sul. Porto Alegre: PUCRS. 1997.

GLAUSER, Marcos. Mapeo territorial de las estrategias de sobrevivencia biológica y cultural en cuatro comunidades Mbya guaraní del Tekoha Guasu Reserva San Rafael, Paraguay. Tesis de Máster en Agroecología. Universidad Internacional de Andalucía, España. 2012.

KRAMER, Ana María Gorosito. Liderazgos guaraníes. Breve revisión histórica y nuevas notas sobre la cuestión. Avá Revista de Antropología, n.9, p. 11-27, 2006.

KRAMER, Ana María Gorosito. Encontros e desencontros. Relações interétnicas e representações em Misiones (Argentina). Dissertação de mestrado, Programa de Pós-Graduação em Antropologia, UnB, 1982.

GUBER, Rosana. La etnografía. Método, campo y reflexividad. Colombia: Grupo Editorial Norma, 2001.

LADEIRA, Maria Ines. Espaço Geográfico Guaraní-Mbyá: significado, constituição e uso. São Paulo: EDUSP, 2008.

LARRICQ, Marcelo. Ypytuma. Construcción de la persona entre los Mbya-Guaraní. Posadas: Editorial Universitaria de la UnaM,1993. 
LEHNER, Beate. ¿Qué es un territorio tradicional indígena?. In: LEHNER, B. (Org.). Território Indígena. Assunción: S/E, 2008.

LEHNER, Beate. Algunas observaciones sobre la situación socio-política actual de los Paï-Tavyterä. In: MELIÁ, B.; GRÜNBERG, G.; GRÜNBERG, F. (Orgs.). Los Paï Tavyterä. Etnografía guaraní del Paraguay contemporáneo. Asunción: CEADUC-CEPAG. 2008b.

LEHNER, Beate. Los Pueblos Guaraní del Paraguay Oriental. Disponível em: < http://guarani.roguata.com/sites/default/files/text/file/uid110/lehnerlospueblosguaranidelaregionorienta lpy.pdf >. Acesso em: julho de 2018.

MELIÁ, Bartomeu. Mundo Guaraní. 2 Edición, Asunción: Servilibro, 2011.

MELIÁ, Bartomeu; GRÜNBERG, Georg; GRÜNBERG, Friedl Paz. Paĩ-Tavyterã. Etnografía guaraní del Paraguay Contemporáneo. $2^{\mathrm{a}}$ ed. Asunción: CEADUC-CEPAG. 2008.

MELIÁ, Bartomeu. El guaraní conquistado y reducido. Ensayos de etnohistoria. Asunción: CEADUC, 1986.

SILVA, Evaldo Mendes da. Folhas ao vento a micromobilidade de grupos Mbya e Nhandéva (Guarani) na Tríplice Fronteira. Tese de doutorado apresentada ao Programa de Pós-Graduação em Antropologia Social Museu Nacional da Universidade Federal do Rio de Janeiro, 2007.

MURA, Fabio. Beyond nature and the supernatural: some reflections on religion, ethnicity and traditions of knowledge. Vibrant, v.11, n. 2, 2014.

MURA, Fabio. À procura do "bom viver": território, tradição de conhecimento e ecologia doméstica entre os Kaiowa. Rio de Janeiro: UFRJ/ MN/PPGAS, 2006.

NOELLI, Francisco. Sem Tekohá não há Tekó (Em busca de um modelo etnoarqueológico da aldeia e da subsistência Guarani e sua aplicação a uma área de domínio no delta do rio Jacuí. Porto Alegre: PUC, 1993. OVERING, Joanna; PASSES, Alan. The anthropology of Love and Anger. The Aesthetics of Conviviality in Native Amazonia. London: Routledge-Taylor \& Francis Group, 2000.

PISSOLATO, Elizabeth. A duração da pessoa: mobilidade, parentesco e xamanismo mbya (guarani). Tesis de Doctorado, Museo Nacional, Universidade Federal do Rio de Janeiro, mimeo. São Paulo: Editora Unesp; Rio de Janeiro: Nuti, 2006.

Propiedad Intelectual Colectiva del Pueblo Mbyá Guaraní - Asociación Tekoa Yma Jeea Pave. Mapeo y Gestión Territorial de 7 comunidades indígenas del Pueblo Mbyá: Bases de la Asociación Tekoa Yma Jeea Pave, Caazapá. Realizado por: Asociación Tekoa Yma Jeea Pave. Con el apoyo de: AlterVida, Centro de Estudios y Formación para el Ecodesarrollo, Cooperación Alemana Deutsche Zusammenarbeit, GIZ. Paraguay. 2016.

Propiedad Intelectual Colectiva del Pueblo Mbyá Guaraní. Informe final del mapeo comunitario participativo de la ocupación, uso y conocimiento tradicional del Pueblo Mbyá Guaraní de Itapúa y Caazapá respecto a sus tierras, territorio y recursos naturales. Elaborado por: Asociación de Comunidades 
Indígenas de Itapúa (ACIDI), Asociación TekohaYmaJee'aPavë, y Alter Vida, Centro de Estudios y Formación para el Ecodesarrollo. Paraguay. 2013.

Propiedad Intelectual Colectiva del Pueblo Mbyá Guaraní. Estudio y Mapeo Comunitario Participativo de la Ocupación, Uso y Conocimiento Tradicional del Pueblo Mbyá Guaraní de Itapúa y Caazapá respecto a sus Tierras, Recursos Naturales y una Propuesta de Plan de Manejo sobre su Tekoha Guasú. Asociación de Comunidades Indígenas de Itapúa (ACIDI) y Asociación TekohaYmaJee'aPavë. Paraguay. 2009.

RENHFELDT, Marilin. Notas sobre la situación de los Guaraní en el Paraguay contemporáneo. LaRivada, v. 1, ก. 1, 2013.

REMORINI, Carolina. Crecer en movimiento. Abordaje etnográfico del desarrollo infantil en comunidades Mbya (Argentina). Revista Latinoamericana de Ciencias Sociales sobre Niñez y Juventud, v. 8, n. 2, 2010.

RODRÍGUEZ, Carolina; GLAUSER, Marcos. Mapeo Participativo en parte del Tekoha Guasu, territorio mbyá guaraní. Avá Revista de Antropología, n. 24, 2014, p.85-106

SALAMANCA, Carlos. Alecrín. Cartografías para territorios en emergencia. Rosario: UNR Editora, 2012.

SUSNIK, Branislava. Etnohistoria del Paraguay. Etnohistoria de los Chaqueños y de los Guaraníes. Bosquejo sintético. Suplemento Antropológico, v. XXIII, n. 2,1998.

Recebido em 30 de dezembro de 2017. Aprovado em 01 de julho de 2018 